\author{
Part of Journal of Research of the National Bureau of Standards, Volume 31, \\ September 1943
}

\title{
DENSITY OF LEATHER AND ITS SIGNIFICANCE
}

\author{
By Joseph R. Kanagy and Everett L. Wallace
}

\section{ABSTRACT}

The real density of leather calculated from the weight of a measured volume, allowing for voids, and the apparent density of leather calculated from the weight of a measured volume, not allowing for voids, were studied. The real-density values of different samples of leather and a sample of raw hide were determined by a method in which Boyle's law is applied. The apparent density of some of these samples, obtained by direct dimensional measurement and by displacement of mercury, is compared with the real density. The real densities of most of the samples vary within a narrow range (1.387 to 1.516), whereas the apparent densities vary over a greater range, depending upon the treatment. For this reason the apparent density is believed to be a more valuable factor for most practical considerations. The influence of location of the specimen on the hide on real density is considered, and results that show the effect of compression on both densities are given. Moisture content is shown to have considerable influence on the real density. For leathers that do not have abnormally high grease contents, the permeabilities to air and water vapor appear to show some correlation to the percentage of voids, which is calculated from the ratio of the apparent to the real density.

\section{CONTENTS}

I. Introduction

II. Apparatus and procedure

III. Results and discussion

1. Comparison of results from dimensional measurements and from displacement of mercury

2. Effect of moisture on the density of leather

3. Comparison of real and of apparent densities

4. Variation of real density with respect to location of specimens on hide

5. Effect of compression on density of leather ........... 177

6. Relation of percentage of voids to physical properties of leather 178

IV. Conclusions_._. 178

V. References

\section{INTRODUCTION}

There are two ways of expressing the density of leather: (1) The real density, which is determined by a method that allows for voids, or free space, in the leather, and (2) the apparent, or bulk, density, which is calculated from a measured volume of leather, not allowing for voids. The ratio of these two values gives an indication of the percentage of voids, or free space, in the leather. The size of the voids 
is difficult to estimate. Air and liquids, such as water and kerosine, penetrate leather easily. On the contrary, mercury, a liquid of high surface tension, and resinous materials in solution having large particle sizes, do not enter the voids. The percentage of voids undoubtedly influences a number of the physical properties of leather, such as watervapor permeability, air permeability, and water absorption.

Apparent density can be determined quite accurately from the weight of a definite volume of leather if the volume is obtained by direct dimensional measurements. The determination of real density is more difficult, and the methods used in the past were subject to considerable criticism. Recently, however, Gallay and Tapp [1] ${ }^{1}$ have applied Boyle's law to determine real densities by a simple method making use of the displacement of air, and which gives results of high precision. Clarke [2] determined real density by a method based on the amount of kerosine displaced by the leather under reduced pressure; he then determined apparent density by the amount of this liquid displaced by the sample saturated with kerosine. Casaburi [3] used a method for determining real density based on the amount of air displaced by the leather. Thuau and Goldberger [4] and Edwards [5] applied methods based on Boyle's law. The former gave no data. Edwards used a complicated procedure, which he admitted was in error by an amount equal to about 1.3 percent.

In this investigation a study of the real and apparent densities of leather was made. Real density was determined with an apparatus similar to that used by Gallay and Tapp, and apparent density was determined by direct dimensional measurement and by the displacement of mercury. The determinations were made on a number of leathers representing different types and tannages. The effects of location of the specimen on the hide and of compressing the specimens were studied. Some data on the influence of moisture content on the real density are given, and the practical significance of the apparent and real densities is discussed.

\section{APPARATUS AND PROCEDURE}

A diagram of the apparatus used to determine real density is shown in figure 1. $A$ is a vessel connected at both ends with capillary tubing. The volume is calibrated between the points on the capillaries $X$ and $Y$ and is equal to $10.734 \mathrm{ml}$. $B$ is another vessel which serves as the container for the samples. It is connected to $A$ with capillary tubing and the three-way stopcock, $F . A$ and $B$ have an outlet through the stopcock $F$ and the U-tube $C$, which contains anhydrous calcium sulfate. The purpose of the anhydrous calcium sulfate is to dry the air drawn into vessel $A$ and prevent the condensation of water vapor in $B$ on compression. The capacity of $B$, including the capillary arm to $Y$, is about $18 \mathrm{ml}$. The cap $H$ fits over the outside of $B$, thereby eliminating the possibility of the leather coming into contact witb the lubricating grease. The cap is fitted with glass lugs and held securely by means of wire springs. $D$ is a cup containing mercury. This is attached to the main apparatus with rubber tubing and is used to raise and lower the mercury level in $A$.

The density determinations are made exactly as described by Gallay and Tapp [1]. With $F$ open to the U-tube, $C$, and the vessel

\footnotetext{
1 Figures in brackets indicate the literature references at the end of this paper.
} 


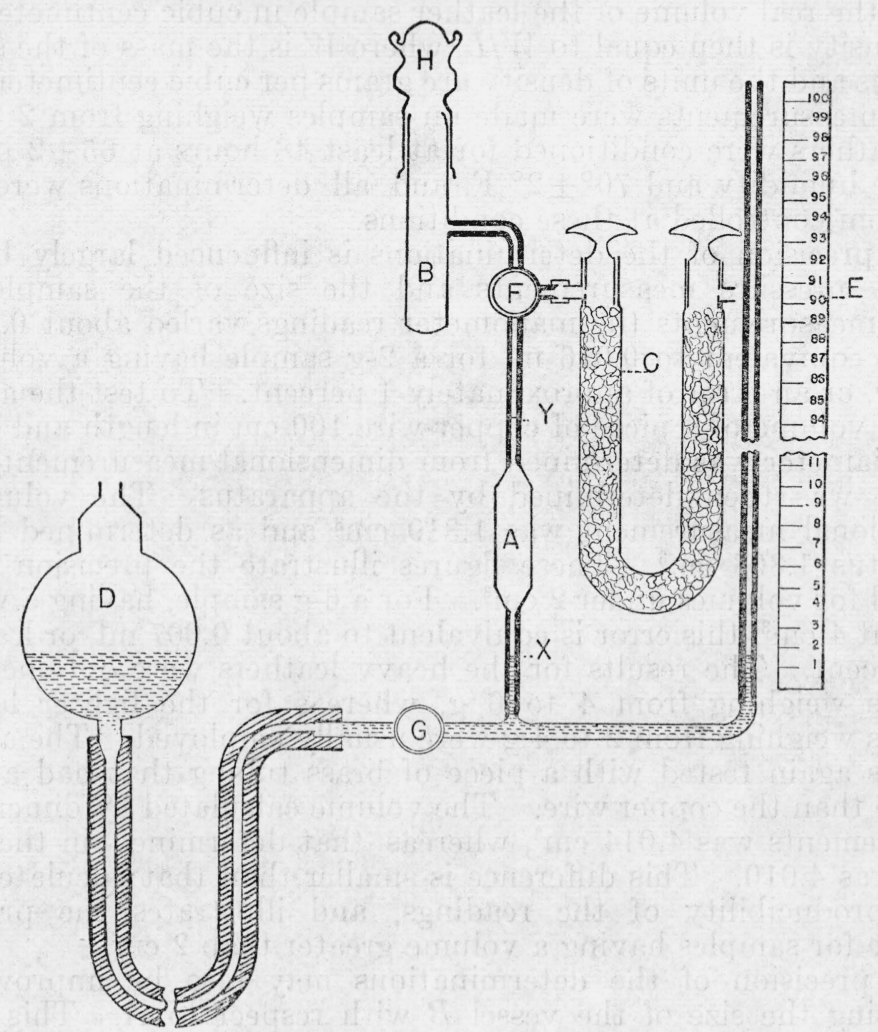

Figure 1.-Diagram of the apparatus used to determine real density.

$A$, the mercury level in $A$ is raised to $Y$ by lifting the mercury cup $D$. Then dry air is drawn from $C$ into $A$ by lowering the mercury to $X$. $F$ is closed to $C$ and opened to $A$ and $B$. The sum of the volumes of $A$ and $B$ and the connecting capillaries is $V_{1} . P_{1}$ is the barometric pressure, $P$. The mercury level is then raised from $X$ to $Y ; G$ is closed. The capacity of $B$ and the capillary arm to $Y$ is $V_{2}$, and the barometric pressure, $P$, plus the increase in pressure shown on manometer $E$, caused by the compression, $\Delta P_{1}$, is $P_{2}$. All values of pressure are read in centimeters of mercury. Then substituting in Boyles law equation for a given mass of gas at a given temperature,

or

$$
\begin{gathered}
P_{1} V_{1}=P_{2} V_{2} \\
P(A+B)=\left(P+\Delta P_{1}\right) B,
\end{gathered}
$$

$$
B=\frac{P A}{\Delta P_{1}} .
$$

From this equation the volume of $B$ is calculated. When a leather specimen with volume $L$ is placed in $B$ and the procedure repeated, the following equation holds:

$$
\begin{aligned}
P(A+B-L) & =\left(P+\Delta P_{2}\right)(B-L), \\
L & =B-\frac{P A}{\Delta P_{2}} .
\end{aligned}
$$


If $L$ is the real volume of the leather sample in cubic centimeters, the real density is then equal to $W / L$, where $W$ is the mass of the sample in grams and the units of density are grams per cubic centimeter.

The measurements were made on samples weighing from 2 to $6 \mathrm{~g}$. The leathers were conditioned for at least 48 hours at $65 \pm 2$ percent relative humidity and $70^{\circ} \pm 2^{\circ} \mathrm{F}$, and all determinations were made in a room controlled at these conditions.

The precision of the determinations is influenced largely by two factors-pressure measurements and the size of the sample. On repeat measurements the manometer readings varied about $0.5 \mathrm{~mm}$. This is equivalent to $0.016 \mathrm{ml}$ for a $2-\mathrm{g}$ sample having a volume of $1.5 \mathrm{~cm}^{3}$, or an error of approximately 1 percent. To test the apparatus the volume of a piece of copper wire $100 \mathrm{~cm}$ in length and of uniform diameter was determined from dimensional measurements. Its volume was then determined by the apparatus. The volume by dimensional measurement was $1.319 \mathrm{~cm}^{3}$ and as determined by the apparatus $1.303 \mathrm{~cm}^{3}$. These figures illustrate the precision of the method for volumes under $2 \mathrm{~cm}^{3}$. For a 6 -g sample, having a volume of about $4 \mathrm{~cm}^{3}$, this error is equivalent to about $0.007 \mathrm{ml}$, or less than 0.2 percent. The results for the heavy leathers were obtained with samples weighing from 4 to $6 \mathrm{~g}$, whereas for the lighter leathers samples weighing from 2 to $4 \mathrm{~g}$ were usually employed. The apparatus was again tested with a piece of brass tubing that had a larger volume than the copper wire. The volume calculated by dimensional measurements was $4.014 \mathrm{~cm}^{3}$, whereas that determined in the apparatus was 4.010. This difference is smaller than that calculated from the reproducibility of the readings, and illustrates the precision possible for samples having a volume greater than $2 \mathrm{~cm}^{3}$.

The precision of the determinations may also be improved by decreasing the size of the vessel $B$ with respect to $A$. This would increase $\Delta P_{1}$, and an error of $0.5 \mathrm{~mm}$ in reading the scale would amount to a smaller percentage.

The apparent density was determined by calculation from dimensional measurements and by displacement of mercury, using apparatus similar to that described by Rose [8]. Figure 2 is a sketch of this apparatus. $A$ is a glass vessel used as the container for the leather samples. It is fitted with a cap to which a capillary tube is attached open to the atmosphere. The volume-measuring device, $G, H, I$, consists of two graduated pipettes connected to the ends of a glass bulb. The pipettes are graduated in hundred ths of a cubic centimeter, and the volume can be estimated to $0.002 \mathrm{~cm}^{3}$. The capacity of the glass bulb and the tubing between the bulb and the graduations were determined by calibration with mercury. The capacity of the bulb is approximately $8.5 \mathrm{ml}$, and the size of the sample that can be used is limited to the sum of this capacity and that of the two pipettes, which is approximately $10.5 \mathrm{ml}$.

The determinations are made as follows: Reduction of the pressure by a vacuum pump attached to $E$ introduces, through $C$, sufficient mercury to fill the vessel $A$ and the capillary to the level $F$ and to reach a level higher than $F$ on the graduated part of the pipette, $G$. $C$ is closed, and the mercury is held at this level by also closing $B$. The reading of pipette $G$ is recorded. The three-way stopcock, $E$, is 


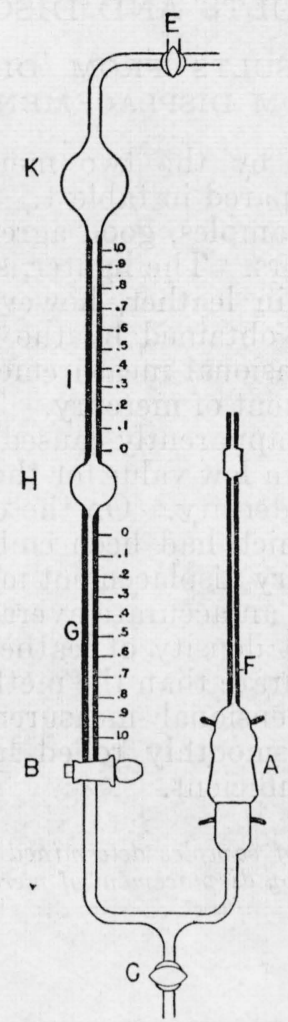

Figure 2.-Diagram of the apparatus used to determine apparent density.

then opened to the vacuum pump. Stopcock $B$ is also opened, and the mercury is drawn into $K$ until the level in $A$ is lowered sufficiently to allow space for the leather specimen. $B$ is then closed to hold the mercury in $K$, and $E$ is opened to the atmosphere. After the sample has been placed in $A$, the mercury is permitted to reenter $A$ by operating the stopcock $B$ until the level again reaches the point $F$ on the capillary. The reading on pipette $I$ is then recorded. From the readings of the pipettes and the capacity of bulb $H$, the volume of mercury displaced by the leather sample is determined.

Repeated determinations on the same sample of leather gave values that differed by not more than $0.005 \mathrm{~cm}^{3}$. This would be equivalent to an error of 0.05 percent for a sample having a volume of $10 \mathrm{ml}$, which is the approximate size of the samples used.

The determinations of apparent density by dimensional measurements were made on samples approximately 2 by 4 inches. The thickness of each sample was determined in six different places with a Randall Stickney gage having a foot $3 / 8$ inch in diameter and a load of 1 pound. The average thickness was used in the calculation. The samples were conditioned, and all the measurements were made at $70^{\circ} \mathrm{F}$ and 65 percent relative humidity. 


\section{RESULTS AND DISCUSSION}

\section{COMPARISON OF RESULTS FROM DIMENSIONAL MEASURE- MENTS AND FROM DISPLACEMENT OF MERCURY}

Some results obtained by the two methods used to determine apparent density are compared in table 1 . Where the detrminations were made on the same samples, good agreement is evident in most cases for the heavy leathers. The lighter, softer, upper leathers and the formaldhyde buckskin leather, however, all show appreciable differences in the results obtained by the two methods. Here the results obtained by dimensional measurement are higher than those obtained by the displacement of mercury. The weight on the presser foot of the thickness gage apparently caused a compression of the soft leathers which resulted in a low value for the thickness and, therefore, gave high results for the density. On the contrary, the chrome sole leather, the surface of which had been embossed, showed a slightly higher value by the mercury displacement method because the presser foot was too large to give an accurate average thickness. For determinations of the apparent density of leathers, the mercury displacement method is more accurate than the method based on dimensional measurements. The dimensional measurements method, however, may be satisfactory for smoothly rolled heavy leathers, where an accuracy of 5 percent is sufficient.

TABLE 1.-Apparent density of samples determined by dimensional measurements and by displacement of mercury

\begin{tabular}{c|c|c}
\hline \hline Leather & $\begin{array}{c}\text { Dimensional } \\
\text { measure- } \\
\text { ments }\end{array}$ & $\begin{array}{c}\text { Displace- } \\
\text { ment of } \\
\text { mercury }\end{array}$ \\
\hline
\end{tabular}

DIFFERENT SAMPLES OF THE SAME TYPES OF LEATHERS

\begin{tabular}{|c|c|c|}
\hline $\begin{array}{l}\text { Finders, sole leather } \\
\text { Chestnut-tanned at NBS } \\
\text { Quebracho tanned at NBS } \\
\text { Austrian sole leather (finders) }\end{array}$ & $\begin{array}{r}\mathrm{g} / \mathrm{cm}{ }^{3} \\
\text { a } 1.15 \\
0.72 \\
.76 \\
1.07\end{array}$ & $\begin{array}{r}\mathrm{g} / \mathrm{cm}^{3} \\
1.110 \\
0.727 \\
.790 \\
1.106\end{array}$ \\
\hline
\end{tabular}

SAME SAMPLES OF THE SAME TYPES OF LEATHERS

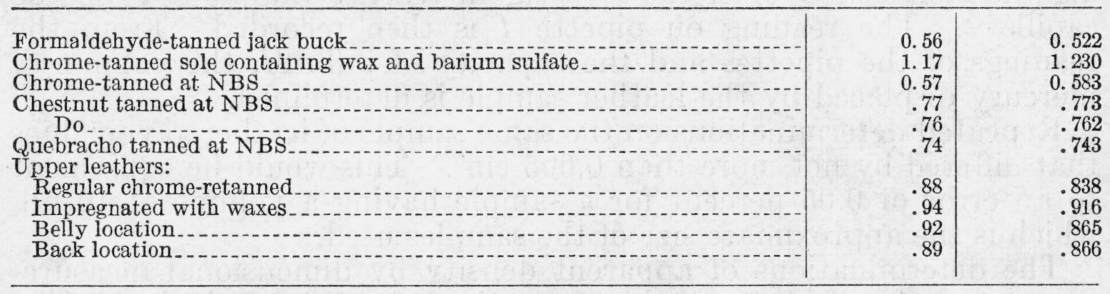

a Average of 35 samples.

\section{EFFECT OF MOISTURE ON THE DENSITY OF LEATHER}

An important variable factor affecting the composition and physical properties of leather is the moisture content. The influence of moisture on the density of leather would be expected to be extremely important. Chestnut and quebracho leathers tanned at the National 
Bureau of Standards were dried by heating at $100^{\circ} \mathrm{C}$ for 4 hours and then placed in an atmosphere of 65-percent relative humidity and - $70^{\circ} \mathrm{F}$. The real densities of these samples were determined before drying, immediately after drying, 1 hour after drying, and 20 hours after drying. The results are given in table 2 . The increase in the real density of the chestnut leather on drying is 0.132 , whereas that of the quebracho leather is 0.157 . The real densities decrease on reconditioning as the samples increase in weight by regaining moisture. These results indicate that any value of the density of leather should be accompanied by a statement of the relative humidity and the temperature at which it was determined.

TABLE 2.-Influence of drying on the real density of leather

\begin{tabular}{|c|c|c|c|}
\hline Leather & Mass & Volume & Real density \\
\hline \multicolumn{4}{|c|}{ BEFORE DRYING } \\
\hline $\begin{array}{l}\text { Chestnut } \\
\text { Quebracho }\end{array}$ & $\begin{array}{l}{ }_{2} .335 \\
2.884\end{array}$ & $\begin{aligned} & c m^{3} \\
& 1.614 \\
& 2.080\end{aligned}$ & $\begin{array}{c}\mathrm{g} / \mathrm{cm} \mathrm{s}^{3} \\
1.447 \\
1.387\end{array}$ \\
\hline \multicolumn{4}{|c|}{ IMMEDIATELY AFTER DRYING } \\
\hline $\begin{array}{l}\text { Chestnut } \\
\text { Quebracho }\end{array}$ & $\begin{array}{l}\text { 2. } 024 \\
\text { 2. } 503\end{array}$ & $\begin{array}{l}\text { 1. } 282 \\
1.621\end{array}$ & $\begin{array}{l}1.579 \\
1.544\end{array}$ \\
\hline \multicolumn{4}{|c|}{1 HOUR AFTER DRYINA } \\
\hline $\begin{array}{l}\text { Chestnut } \\
\text { Quebracho }\end{array}$ & $\begin{array}{l}2.135 \\
2.633\end{array}$ & $\begin{array}{l}1.385 \\
1.752\end{array}$ & $\begin{array}{l}1.542 \\
1.503\end{array}$ \\
\hline \multicolumn{4}{|c|}{20 HOURS AFTER DRYING } \\
\hline $\begin{array}{l}\text { Chestnut } \\
\text { Quebracho }\end{array}$ & $\begin{array}{l}2.296 \\
2.860\end{array}$ & $\begin{array}{l}1.572 \\
2.027\end{array}$ & $\begin{array}{l}1.461 \\
1.411\end{array}$ \\
\hline
\end{tabular}

\section{COMPARISON OF REAL AND OF APPARENT DENSITIES}

Values for the real densities of 21 different samples of leather and for raw hide are shown in table 3. Values for the apparent densities obtained by dimensional measurements of some of the samples are also given. The leather samples represent different tannages as well as different types. The real densities of all the samples except the two chrome-retanned upper leathers, which contain high percentages of grease, vary within rather narrow limits of 1.387 to 1.516 . It is interesting to note that Clarke [2], who determined the real densities by a different method, also found that these values varied within narrow limits. His results, however, were lower, ranging from 1.327 to 1.433 . In general, the tanned leathers have higher densities than rawhide. Chestnut leather has a higher real density than quebracho leather. Salts increase but greases decrease the real density. In fact, the real density of leather seems to be a function of the densities of the individual constituents and their percentages in a given sample. 
TABLE 3.-Comparison of real-and apparent-density values

\begin{tabular}{|c|c|c|}
\hline Description of material & $\begin{array}{l}\text { Apparent } \\
\text { density from } \\
\text { dimensional } \\
\text { measure- } \\
\text { ments }\end{array}$ & $\begin{array}{l}\text { Real } \\
\text { density }\end{array}$ \\
\hline Raw hide, dehydrated with alcohol. & $\mathrm{g} / \mathrm{cm}^{3}$ & $\begin{array}{r}\mathrm{g} / \mathrm{cm}^{3} \\
1.38\end{array}$ \\
\hline $\begin{array}{l}\text { Leathers tanned in experimental tannery at NBS: } \\
\text { Chrome-tanned steer hide. }\end{array}$ & 0.57 & \\
\hline $\begin{array}{l}\text { Qron-tanned steer hide } \\
\text { Quebracho-tanned steer hide } \\
\text { Quebracho-tanned steer hide containing glucose and salts } \\
\text { Quebracho-tanned steer hide containing sulfited quebracho } \\
\text { Chestnut-tanned steer hide } \\
\text { Chestnut-tanned steer hide containing glucose and salts. } \\
\text { Chestnut-tanned steer hide containing sulfited quebracho }\end{array}$ & $\begin{array}{r}.76 \\
.83 \\
.81 \\
.72 \\
.83 \\
.81\end{array}$ & $\begin{array}{l}\text { 1. } 410 \\
\text { 1. } 387 \\
\text { 1. } 400 \\
\text { 1. } 415 \\
\text { 1. } 447 \\
\text { 1. } 470 \\
1.439\end{array}$ \\
\hline $\begin{array}{l}\text { Light leathers: } \\
\text { Formaldehyde-tanned buckskin } \\
\text { Chrome-retanned upper } \\
\text { Chrome-retanned upper containing waxes. }\end{array}$ & $\begin{array}{l}.56 \\
.88 \\
.94\end{array}$ & $\begin{array}{l}1.516 \\
1.338 \\
1.327\end{array}$ \\
\hline $\begin{array}{l}\text { Sole leathers: } \\
\text { Factory } \\
\text { Finders } \\
\text { Chrome containing wax and barium sulfate } \\
\text { Vegetable-high grease content } \\
\text { Vegetable-thin } \\
\text { Vegetable-thick } \\
\text { Vegetable-low load } \\
\text { Vegetable-high load } \\
\text { Vegetable containing approximately } 10 \% \text { of } 0 \text { gil }\end{array}$ & $\begin{array}{r}1 \\
11.03 \\
1.15 \\
1.17\end{array}$ & $\begin{array}{l}1.461 \\
1.494 \\
1.465 \\
1.394 \\
1.472 \\
1.463 \\
1.464 \\
1.434 \\
1.440 \\
1.393\end{array}$ \\
\hline
\end{tabular}

${ }^{1}$ Average of 35 samples.

In most cases, the samples with the highest apparent densities also have the highest real-density values. Formaldehyde-tanned jack buck leather is an exception. It has the highest real density and the lowest apparent density. An increase in the apparent density caused by a definite treatment of a certain sample of leather, however, is usually accompanied by a much smaller increase in the real density of the leather. This obviously is to be expected, since the addition of salts or grease to a leather merely fills the voids and results in no appreciable change of the apparent volume. The difference between the apparent-density values of chrome-tanned steer hide and the chrome-tanned sole leather filled with barium sulfate and wax is $0.60 \mathrm{~g} / \mathrm{cm}^{3}$, whereas that of the real density is only $0.056 \mathrm{~g} / \mathrm{cm}^{3}$. As another example, the results obtained with factory and finders leather may be compared. Here the principal difference in the physical properties is the greater firmness of the finders leather. The difference between the apparent-density values is $0.12 \mathrm{~g} / \mathrm{cm}^{3}$, whereas that of the real density is $0.033 \mathrm{~g} / \mathrm{cm}^{3}$. For most practical applications, as in a specification where a leather having a definite physical characteristic related to density is desired, a specified apparent density would appear to have more significance than a specified real density.

\section{VARIATION OF REAL DENSITY WITH RESPECT TO LOCATION OF SPECIMENS ON HIDE}

The effect of location of the specimens on the hide on the real density of leather was studied with both light upper leather and heavy sole leather. The upper-leather samples were cut from sides. One sample was taken from the backbone $(A)$ location, the other was cut 
from the belly edge near the shoulder. The heavy-leather samples were cut from sole-leather bends; the locations were approximately the same as those of the upper leathers. Determinations were made on the sole leathers with their original composition intact except for conditioning and after they had been degreased, washed, and reconditioned. The results are shown in table 4 . There appears to be no appreciable variation that can be attributed to the location of the sample; small variations occur in both directions, but these are possibly due to differences in salt or moisture contents and partly to experimental error. Washing has definitely lowered the real density, most probably because salts are removed.

TABLE 4.-Variation of real density with location of the specimen on the hide

\begin{tabular}{|c|c|c|c|c|}
\hline & $\begin{array}{l}\text { Backbone } \\
\text { location }^{1}\end{array}$ & $\begin{array}{l}\text { Belly loca- } \\
\text { tion } 1\end{array}$ & $\begin{array}{l}\text { Backbone } \\
\text { location }^{2}\end{array}$ & $\begin{array}{c}\text { Belly loca- } \\
\text { tion? }\end{array}$ \\
\hline Upper leather ${ }^{3}$ & $\mathrm{~g} / \mathrm{cm}^{3}$ & $\begin{array}{l}\mathrm{g} / \mathrm{cm}^{3} \\
1.482\end{array}$ & $\mathrm{~g} / \mathrm{cm}^{3}$ & $\mathrm{~g} / \mathrm{cm}^{3}$ \\
\hline $\begin{array}{l}\text { Do }{ }^{3} \\
\text { Sole leather } A\end{array}$ & $\begin{array}{l}1.443 \\
1.434\end{array}$ & $\begin{array}{l}1.429 \\
1.447\end{array}$ & 1. 422 & 1.43 \\
\hline $\begin{array}{l}\text { Sole leather } B \\
\text { Sole leather } C\end{array}$ & 1. 449 & 1. 475 & $\begin{array}{l}1.430 \\
-1.4\end{array}$ & 1.421 \\
\hline Sole leather $C$. & 1.455 & 1.446 & 1.429 & 1. 444 \\
\hline
\end{tabular}

1 Unwashed.

2 Degreased and washed.

3 Upper leather was degreased but not washed.

\section{EFFECT OF COMPRESSION ON DENSITY OF LEATHER}

The leather was conditioned at $70^{\circ} \mathrm{F}$ and 65 percent relative humidity for 48 hours. Fifteen percent by weight of water was then added to the conditioned samples. The samples were placed in a container at 100 -percent relative humidity for 16 hours. They were then subjected to a pressure of $3,000 \mathrm{lb} / \mathrm{in}^{2}{ }^{2}$ in a hydraulic press for 2 or 3 minutes, after which they were dried and reconditioned. Real- and apparent-density measurements were made on the samples both before and after compression. The results are shown in table 5. Real density does not change on compression. The apparent density, however, changes considerably, depending upon the original value. A maximum value for apparent density appears to be reached, under the conditions prevailing at 1.06 to $1.14 \mathrm{~g} / \mathrm{cm}^{3}$. If the apparent density is originally lower, it reaches a value in this range after compression; if the original apparent density lies within this range, it changes very little after compression.

TABLE 5.-Effect of compression on the density of leather

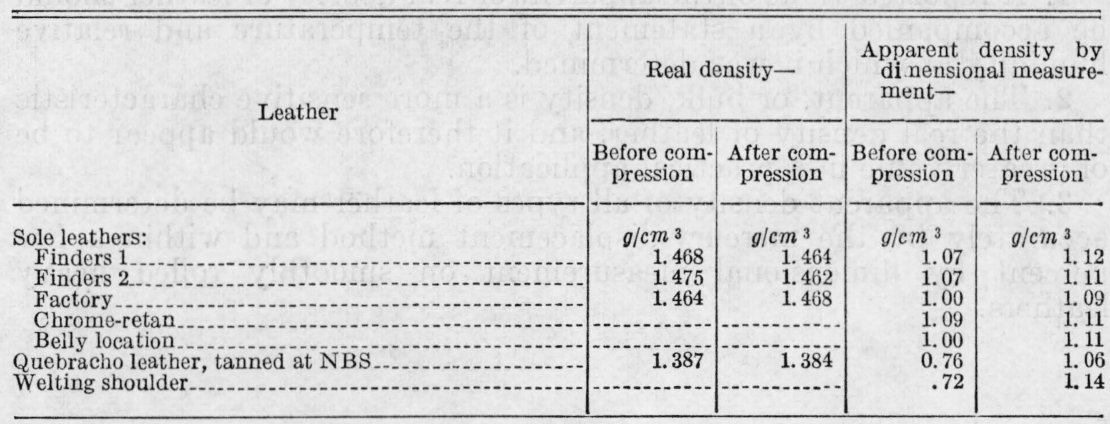




\section{RELATION OF PERCENTAGE OF VOIDS TO PHYSICAL PROPERTIES OF LEATHER}

The percentage of voids in a given sample of leather may be calculated from the equation

$$
X=100\left(1-\frac{D_{a}}{D_{r}}\right)
$$

where $X$ is the percentage of voids, $D_{a}$ the apparent density, and $D_{r}$ the real density. In table 6 are presented the air permeabilities, water-vapor permeabilities, and percentage of voids of several leathers. Air permeability was determined by the method and apparatus developed by Carson [6]. Water-vapor-permeability measurements were made by the method described by Hobbs [7]. For leathers which do not have abnormally high grease contents there appears to be some correlation between the percentage of voids and their permeabilities to air or water vapor. However, those leathers which have high grease contents, such as the chrome-tanned sole leather and the chrome-tanned upper leather treated with waxes, show low watervapor and air permeabilities without a comparable decrease in the percentage of voids. This may be caused by the fact that the grease concentrated in the outer surface of the leather forms a barrier to air and moisture without decreasing appreciably the percentage of voids in the leather as a whole.

TABLE 6.-Comparison of air and water-vapor permeabilities of the leathers with the percentage of voids

\begin{tabular}{|c|c|c|c|c|}
\hline Description of leather & Thickness & $\begin{array}{l}\text { Percent- } \\
\text { age of } \\
\text { voids }\end{array}$ & $\underset{\substack{\text { permeabil- } \\
\text { ity }}}{\text { Air }}$ & $\begin{array}{l}\text { Water- } \\
\text { vapor per- } \\
\text { meability }\end{array}$ \\
\hline $\begin{array}{l}\text { Chrome sole containing barium sulfate and wax } \\
\text { Finders sole. } \\
\text { Chrome-retanned upper containing waxes } \\
\text { Factory sole. } \\
\text { Chrome-retanned upper } \\
\text { Quebracho-tanned steer hide } \\
\text { Chestnut-tanned steer hide }{ }^{2} \\
\text { Chrome-tanned steer hide }{ }^{2} \\
\text { Formaldehyde-tanned jack buck }\end{array}$ & $\begin{array}{c}\text { Inches } \\
0.200 \\
.240 \\
.080 \\
.185 \\
.075 \\
.170 \\
.190 \\
.230 \\
.090\end{array}$ & $\begin{array}{l}20 \\
23 \\
29 \\
30 \\
34 \\
45 \\
50 \\
60 \\
63\end{array}$ & $\begin{array}{c}(m l / s e c) m^{2} \\
0.70 \\
9.5 \\
0 \\
3.8 \\
7.2 \\
38 \\
64 \\
38 \\
5540\end{array}$ & $\begin{array}{c}\left.\left(g / m^{2}\right) / d a y\right) \\
28.3 \\
283 \\
0 \\
266 \\
360 \\
537 \\
554 \\
492 \\
900\end{array}$ \\
\hline
\end{tabular}

1 Contains high percentage of grease or waxes.

2 Tanned in experimental tannery at National Bureau of Standards.

\section{CONCLUSIONS}

1. A reported value of the apparent or real density of leather should be accompanied by a statement of the temperature and relative humidity at which it was determined.

2. The apparent, or bulk, density is a more sensitive characteristic than the real density of leather, and it therefore would appear to be of greater value in a practical application.

3. The apparent density of all types of leather may be determined accurately by the mercury-displacement method and within a few percent by dimensional measurement on smoothly rolled heavy leathers. 
4. Apparent density of leather appears to reach a maximum value beyond which it cannot easily be increased by a pressure of 3,000 $\mathrm{lb} / \mathrm{in}^{2}$.

5. There appears to be some correlation between the percentage of voids in leather and its permeability to air or to water vapor if grease or wax is not present in large amounts.

\section{REFERENCES}

[1] W. Gallay and J. S. Tapp, J. Am. Leather Chem. Assn. 3\%, 140 (1942).

[2] I. D. Clarke, Ind. and Eng. Chem. 23, 62 (1931).

[3] V. Casaburi, J. Int. Soc. Leather Trades Chem. 22,261 (1938).

[4] J. Thuau and A. Goldberger, J. Int. Soc. Leather Trades Chem. 15,415 (1931).

[5] R. S. Edwards, J. Int. Soc. Leather Trades Chem. 17, 358 (1933).

[6] Frederick T. Carson and Vernon Worthington, J. Research NBS 26, 467 (1941) RP1390.

[7] Robert B. Hobbs, J. Am. Leather Chem. Assn. 36, 346 (1941).

[8] Henry Rose, J. Am. Leather Chem. Assn. 38, 107 (1943).

Washington, June 25, 1943. 